\title{
LA CONCEPCIÓN DEL SUJETO EN LOS ESTUDIOS SOBRE EL RIESGO Y LA PRUEBA DEL VIH EN HSH ${ }^{1}$
}

\author{
THE CONCEPT OF SUBJECT IN RESEARCH ON HIV \\ RISK-TAKING AND TESTING AMONG MSM \\ FERNANDO VILLAAMIL, MARÍA ISABEL JOCILES y \\ FERNANDO LORES \\ Universidad Complutense de Madrid
}

\begin{tabular}{ll}
\hline PALABRAS CLAVE ADICIONALES & ADDITIONAL KEYWORDS \\
HSH, Diversidad de Racionalidades, Promoción & MSM, Diversity of Rationalities, Health \\
de la salud. & Promotion.
\end{tabular}

RESUMEN. En este artículo se expone un modelo de análisis elaborado a partir de los resultados de una investigación realizada a iniciativa del Instituto de Salud Pública de la Comunidad de Madrid en torno a la práctica de la prueba del VIH y las construcciones del riesgo de los hombres que tienen relaciones sexuales con hombres (HSH). Se trata de una investigación encaminada a proponer estrategias de intervención en el campo de la promoción de la salud entre HSH. Se concluye que, a la hora de abordar la investigación ligada a la intervención en prevención del VIH, es imprescindible el manejo de una teoría solvente y explícita del sujeto social.

\begin{abstract}
In this paper we put forward a model for analysis which is based on the results of a research project about practices of HIV testing and constructions of risk among men who have sex with men (MSM) that was started by a demand of the Institute of Public Health of the Region of Madrid. The research was intended to propose strategies of intervention in the field of health promotion among MSM. We conclude that a sound and explicit theory of the social subject is indispensable for researching in the field of HIV preventive interventions.
\end{abstract}

\footnotetext{
I Otra versión de este artículo ha sido publicada en Sociologia: problemas e prática 47; en dicha versión hemos presentado otros resultados de investigación, si bien bajo el mismo contraste de modelos teóricos desplegado aquí.

E-mail: jociles@cps.ucm.es villaamil@cps.ucm.es lores_masip@yahoo.es
}

Revista Internacional de Sociología (RIS)

Tercera Época, No 42, Septiembre-Diciembre, 2005, pp. 69-99 
RIS

REVISTA INTERNACIONAL DE SOCIOLOGÍA

№ 42, SEPTIEMBRE-DICIEMBRE, 2005

FERNANDO VILLAAMIL, MARÍA ISABEL JOCILES y FERNANDO LORES

\section{INTRODUCCIÓN}

El tema que abordamos aquí es el de los factores que inciden en la realización o posposición de la prueba de detección de anticuerpos frente al VIH (a partir de ahora, prueba del VIH o, simplemente, prueba) en los HSH (hombres que tienen relaciones sexuales con hombres) madrileños. El análisis que realizaos se basa en los resultados de una investigación (llevada a cabo en el marco de un convenio de colaboración entre la Universidad Complutense y el Instituto de Salud Pública de la Comunidad de Madrid) que tiene una finalidad eminentemente aplicada: definir el marco para futuras estrategias de intervención que puedan favorecer el uso de la prueba dentro de dicho colectivo.

La realización de la prueba del VIH ha sido considerada una de las principales estrategias de control de la epidemia, especialmente desde la introducción de terapias eficaces de tratamiento de la infección, capaces de asegurar a una proporción relevante de las personas que viven con VIH una aceptable calidad de vida. Además, un diagnóstico precoz de la infección por VIH mejora sustancialmente el pronóstico, disminuyendo fuertemente las tasas de morbilidad y mortalidad. Sin embargo, las mejoras terapéuticas quedan seriamente comprometidas cuando el diagnóstico es tardío, coincidente con la aparición de enfermedades indicativas de SIDA. Así, las ventajas de conocer el serostatus positivo en una fase temprana de la infección son, en principio, incontrovertibles y, por tanto, la promoción de la prueba debe ser entendida como un ítem imprescindible en la planificación de las actividades de prevención del VIH/SIDA y otras infecciones de transmisión sexual.

Los HSH que residen en Madrid, colectivo en el que se centra el estudio que presentamos, poseen tasas de prevalencia de VIH altas en el contexto europeo (CESES, 2003), que además se encuentran en aumento (Proyecto Epi-VIH, 2003). Los datos disponibles indican que con toda probabilidad los HSH madrileños se han venido infectando a lo largo de los años 90 con tasas de incidencia constantes, lo que se refleja en una edad media al diagnóstico de SIDA que tiende a mantenerse, a diferencia de otros grupos (Boletín Epidemiológico, 2003). A ello se añade sin duda el hecho, resaltado en el informe de vigilancia epidemiológica de 2002 (Boletín Epidemiológico, 2002), de que en la población madrileña de HSH el porcentaje de diagnósticos de SIDA sin diagnóstico previo de infección por VIH se sitúa en un grave $41 \%$ en 2001 . Ello puede contarse entre los factores que derivan en una mediana de supervivencia entre los HSH diagnosticados de SIDA menor que en cualquier otro grupo de transmisión y en un pronóstico de evolución de la enfermedad fuertemente comprometido 2 . Por otra parte,

\footnotetext{
${ }^{2}$ Los datos epidemiológicos referidos corresponden al periodo inmediatamente anterior al comienzo de la investigación, los cuales -en cierto modo- sirvieron para justificar la realización de la misma. Los Boletines Epidemiológicos de la CAM publicados desde 2003 a 2005 no hacen sino remarcar las tendencias que esos datos ponen de manifieto, sobre todo en lo que atañe al diagnóstico simultáneo (y tardío) del VIH y del SIDA en HSH.
} 
y aunque no se dispongan de estudios al respecto para nuestro contexto geográfico, algunos investigadores han señalado (MacKellar et al., 2002: Fennema et al., 2000) que un uso repetido del test del VIH puede ir aparejado a prácticas de riesgo frecuentes, poniendo en cuestión la validez y eficacia de la intervención individual (counselling, consejo o asesoramiento) de la que suele ir acompañado.

En el presente artículo emprendemos una reflexión de carácter general relacionada con la forma en que se conceptualiza - implícita o explícitamente- al sujeto de las prácticas de prevención/de riesgo en la literatura especializada sobre la realización de la prueba del VIH, así como con el modelo de intervención $H I V$ counselling, testing and referral (HIV CTR, consejo, test y derivación) propuesto recientemente por los CDC (Centers for Disease Control). Tras revisar críticamente lo que consideramos rasgos básicos del modelo que denominamos epidemiológico, proponemos una comprensión de los modos en que los $\mathrm{HSH}$ perciben y actúan con respecto a la presencia del VIH que no parta de a prioris acerca de comportamientos adecuados siempre ý en toda circunstancia, y que trate más bien de entender la experiencia de los sujetos desde sus determinaciones socioculturales específicas, como momento necesario en el diseño de intervenciones eficaces. Por último, pondremos a prueba este marco teórico a través del estudio de dos racionalidades de fuerte contraste a la hora de incorporar los mensajes de prevención a la realidad vivida por los sujetos.

Es preciso, sin embargo, hacer antes algunas advertencias. Nótese, en primer lugar, que la literatura acerca de diferentes formatos de HIV CTR (en la que nos fundamentamos para establecer los principios básicos del modelo epidemiológico) no agota necesariamente la temática de la promoción de la prueba del VIH, dado que el consejo es una más entre las estrategias que cabe poner en práctica para favorecer su realización en poblaciones que pueden haber estado expuestas al VIH (desde estrategias de movilización comunitaria a otras emparentadas con el marketing, trabajo de calle, intervenciones grupales...). Una segunda advertencia se deriva del hecho de que los contextos institucionales específicos (atención primaria, centros especializados en el diagnóstico y tratamiento de las enfermedades de transmisión sexual, hospitales, donación de sangre...) en los que se oferta la prueba del VIH representan un escenario, entre otros, para realizar consejo preventivo (preventive counselling, uno de los elementos del HIV CTR), que - según nos consta - es ampliamente utilizado, por ejemplo, en programas de prevención llevados a cabo por organizaciones de gays. Aunque no disponemos de base empírica suficiente para tratar con el rigor necesario el grado y la manera en que en Madrid se está aplicando hoy este u otro modelo por parte de las instituciones implicadas, la experiencia referida por los sujetos entrevistados y el hecho indicado de la dudosa eficacia de las intervenciones pre y post test a la hora de fomentar cambios que disminuyan futuros comportamientos de riesgo, señalan la necesidad de reflexionar acerca de las insuficiencias de lo que se está haciendo. Si nos centramos en el modelo de HIV CTR y, por tanto, en contextos 
RIS

REVISTA INTERNACIONAL DE SOCIOLOGIA

№ 42, SEPTIEMBRE-DICIEMBRE, 2005

FERNANDO VILLAAMIL, MARÍA ISABEL JOCILES y FERNANDO LORES

institucionales en los que el consejo se liga a la realización de la prueba del VIH, es porque partimos de la idea de que el modelo de HIV CTR y la investigación a él asociada, al establecer un estándar ampliamente legitimado y compartido, influyen en la práctica de los agentes encargados de llevarlo a cabo. En la medida en que éstos compartan inadvertidamente los sesgos que hemos detectado en el modelo epidemiológico, esperamos contribuir a una mejora de esa práctica. Defendemos que una explicitación de las prenociones de las que arrancan los agentes de intervención para pensar a los sujetos puede favorecer planteamientos más eficaces y acordes con las prioridades y necesidades realmente sentidas por aquéllos a los que van dirigidas las intervenciones.

\section{EL MODELO EPIDEMIOLÓGICO}

El retraso en la realización de la prueba del VIH es, por tanto, una cuestión grave y ha merecido una considerable atención tanto por parte de los estudios epidemiológicos como de las instituciones encargadas de ofrecer modelos de intervención a los agentes más directamente implicados (Anderson et al., 2001). Deseamos destacar algunos elementos característicos de esta perspectiva, hegemónica en investigación e intervención, con el objetivo de clarificar la especificidad y el contexto en el que se realiza la investigación que sirve de base a este artículo. Así, cabe señalar que los estudios consultados tienden a ocuparse de las 'barreras' y 'facilitadores' que pueden influir en la motivación para hacerse la prueba del VIH, obteniéndose en algún caso interesantes resultados (Spielberg et al., 2003, 2001; Kellerman et al., 2002; Hart et al., 2002; Waddell, 1993). Se ha prestado especial atención a las mejoras en las técnicas disponibles de detección de anticuerpos frente al VIH, así como a la influencia de ciertos aspectos organizativos de las instituciones en las que se realiza la prueba: anonimato, accesibilidad, tiempos de espera (Keenan y Keenan, 2001; Skolnik, 2001; Spielberg, 2003; Summers, 2000).

En cuanto a las actividades de counselling que se realizan (o deberían realizarse) en las instituciones que ofertan la prueba, las preocupaciones de la ya ingente literatura al respecto se centran en la eficacia de diferentes formatos (contenidos $\mathrm{y}$ articulación concreta) de la sesión o sesiones de que consta (Rotheram-Borus y Etzel, 2003; Keenan y Keenan, 2001; Spielberg, 2001). El modelo que se propone como canónico consiste habitualmente en una o más sesiones realizadas cuando se solicita el test y/o en el momento de recoger los resultados, de 15 a 20 minutos de duración. En la primera sesión, se proporciona información encaminada a obtener el consentimiento informado de las personas que acuden voluntariamente. En sucesivas sesiones, se proporciona, por un lado, información respecto a la infección del VIH y su transmisión y, por otro, counselling estrictamente dicho, en el que al cliente "...se le ayuda a identificar los comportamientos específicos que le ponen en riesgo de adquirir o transmitir el VIH y a comprometerse a dar 
pasos para reducir ese riesgo" (Anderson et al., 2001:13). Por tanto, frente a otras estrategias de comunicación más preocupadas por transmitir información en una sola dirección, el counseling, al menos en teoría, tiene como virtud su bidireccionalidad y su voluntad de pivotar en torno al cliente, que ya no es un mero receptor mudo de información, sino que tiene garantizado un espacio en el que articular lo que le pasa. Ello tiene unos límites claros, como enseguida veremos. Además, no hay que perder de vista que cuando se ha estudiado también el grado en que el modelo se adecua a las prácticas reales del personal encargado de llevarlo a cabo (Silvestre et al., 2000; Marks et al., 2002), se han obtenido resultados desalentadores (Beardsell, 1999).

El modelo, en cuanto conjunto de recomendaciones y principios, presenta algunos problemas considerables. En primer lugar, éste, y probablemente la práctica concreta de los profesionales e instituciones que ofertan la prueba, se centran en diagnosticar la presencia del VIH en el organismo de personas que no son conscientes de estar infectadas, sin poner un énfasis parejo en enfocar la prueba como un momento privilegiado para realizar intervenciones que sean a su vez un elemento más de una estrategia de prevención del VIH, encaminada a evitar posibles futuras infecciones. Así, aparece mucho más claramente definido qué hacer a partir de un resultado positivo (derivar al sujeto a tratamiento) que de uno negativo, que se soluciona con un vago plan personal de reducción de riesgos en 'pasos'. A esta concepción medicalizada de la prueba no es ajeno el hecho de que sea personal sanitario el que, en primera instancia, esté encargado de efectuarla. Lo que se pierde aquí es la oportunidad de realizar una intervención en un marco menos estrecho de definición de las necesidades de los sujetos 0 , en su caso, derivar los a otras organizaciones e instituciones que desarrollen programas de prevención más específicos; esto es que algo especialmente lamentable si se tiene en cuenta que se trata de un segmento de la población de HSH que, puesto que ha acudido a hacerse la prueba, es harto probable que haya frecuentado prácticas de sexo no seguro.

En segundo lugar, podemos observar una cierta circularidad que se establece en la relación entre investigación y modelo de intervención, en la medida en que los resultados de la primera apoyan determinadas formas de intervenir en el contexto de la prueba y ciertas medidas para facilitar su uso. A su vez, son las intervenciones basadas en las variaciones sobre el modelo 'probado' las que son posteriormente evaluadas. Lo que parece perderse en el camino es la oportunidad de reflexionar acerca de los presupuestos sobre el sujeto social implícitos en dicho modelo y acerca de los fundamentos teóricos de las intervenciones sociosanitarias. En este sentido, si nos fijamos en lo que se define como problemático con respecto a la prueba del VIH entre $\mathrm{HSH}$, los estudios sustentan la misma lógica que las recomendaciones oficiales, fundamentada ésta en un presupuesto no examinado según el cual existiría una única línea de comportamiento 'racional' con relación a la prueba del VIH, cuyo curso puede ser potenciado, ('facilitadores') 
y sobre todo alterado, por 'barreras' en el correcto camino ${ }^{3}$. Los 'facilitadores' y 'barreras' más habitualmente considerados, tienen que ver como hemos visto, con la técnica y las circunstancias legales e institucionales de la prueba, dando por supuesta la existencia virtual de un sujeto aproblemático que, bajo las debidas condiciones, tomará la decisión adecuada. La promoción de la prueba consiste, entonces, en promover esas condiciones, como acortar los tiempos de espera o facilitar la realización del test en el propio hogar, y los estudios se limitan a tratar de averiguar las 'necesidades y preferencias' de un individuo que carece de atributos, que toma 'decisiones' sin pasado y actúa sin contexto.

Con menor frecuencia se atiende a los factores sociales y culturales que pueden estar incidiendo en cómo y cuándo los sujetos se realizan la prueba. Ello se hace, sin embargo, de forma peculiar: los 'factores culturales' son considerados como lo que puede estar distorsionando la asimilación de la información, o también como lo que debe ser tenido en cuenta por ciertos agentes de intervención (los más cercanos a las 'comunidades' con mayor prevalencia: ya no se espera que sea personal médico, sino más bien 'nativo') para 'modular' (tailoring) los mensajes de prevención en función del 'cliente'. Se trata, de nuevo, de remover los 'obstáculos' que pueden estar interfiriendo en la consecución de un objetivo único y excluyentemente racional, en concordancia con lo expuesto más arriba. Así delimitado, no es de extrañar que el modelo de intervención que se legitima con todo el peso de una institución tan relevante como los CDC se dibuje siguiendo un esquema básicamente confesional, en el que el sanitario debe descubrir tanto los posibles errores de los que el sujeto no sea consciente, como guiarle en la senda del cambio, confeccionando de forma conjunta un plan individualizado de reducción del riesgo con 'pasos' a dar que sean 'asequibles' para el sujeto.

La estrategia de investigación que nosotros hemos seguido es, en este sentido, algo distinta. Nuestro marco de análisis parte de la idea de que la realización o posposición de la prueba del VIH se hace comprensible por su inserción en el conjunto de las prácticas y representaciones sociales que tienen que ver con la economía política del sexo (Lancaster, 1993; Lancaster y Di Leonardo, 1997), es decir, con la producción y circulación de valores relacionados con las categorizaciones sexuales y de género, en torno a las cuales se producen y reproducen

\footnotetext{
${ }^{3}$ A primera vista, el comportamiento correcto con respecto a la prueba del VIH consistiría en realizarla al poco tiempo - tres meses después- de la práctica de riesgo. Pero no está en absoluto claro - al menos en la literatura que comentamos- cómo considerar los casos límite: qué hacer con los que se repiten la prueba sin haber tenido prácticas de riesgo, y con los que intercalan prácticas de riesgo y pruebas frecuentes. Fernyak et al., (2002) concluyen que este último es 'un uso apropiado de un recurso de prevención', cuando desde otra perspectiva es un evidente despilfarro de oportunidades de realizar intervenciones eficaces y bien enfocadas con una población notoriamente en riesgo de contraer el VIH.
} 
relaciones sociales de dominación y un conjunto de relaciones políticas, culturales y jurídicas, imprescindibles para comprender la constitución de la subjetividad con relación al campo de la sexualidad. Estos procesos, que generan también conflictos en torno a la distribución de bienes, recompensas y poderes, constituyen, por tanto, el marco a partir del cual hemos intentado comprender las subjetividades de los HSH y, de este modo, las prácticas relacionadas con la realización o posposición de la prueba del VIH.

\section{HACIA UN MODELO COMPLEJO}

Después de transcurridos más de veinte años de presencia de la epidemia de infección por VIH, no puede sorprender la afirmación de que los HSH en España han incorporado el SIDA a sus prácticas sociales y a sus representaciones de la identidad subjetiva y colectiva. Es por ello por lo que el análisis aquí presentado trata de comprender las diferentes prácticas y representaciones en relación con la infección por VIH, esto es, los diversos modos de incorporación de la gestión de la amenaza del SIDA que, en otros términos, pueden ser considerados como distintas racionalidades ${ }^{4}$ que les otorgan coherencia.

Se parte de la hipótesis de que el par sexo seguro/de riesgo, las representaciones del riesgo, la seropositividad y la prueba se hacen comprensibles en el marco de la conformación de las identidades subjetivas de los HSH. Ello, sin embargo, no se ha producido de forma uniforme en el conjunto de los HSH, de modo que destaca la heterogeneidad de las prácticas y representaciones que se han podido constatar. En parte, a consecuencia de una decisión metodológica inicial de contar con la mayor diversidad posible en la muestra en función de distintas dimensiones (edad, nivel socioeconómico, intención de realizarse la prueba, vinculación al ambiente gay), los sujetos entrevistados y los discursos recogidos en los grupos de discusión ${ }^{5}$ reflejan esa amplia variedad de racionalidades desde las que se vive la epidemia de VIH.

De cara al análisis distinguimos entre dimensiones sociales y culturales de las prácticas de los sujetos, entendiendo por dimensiones culturales, fundamentalmente, los marcos de sentido que manejan, concebidos como un conjunto interrelacionado de significados a través de los cuales se percibe la realidad y se orienta la acción, que son articulados en contextos concretos y desde una experiencia y trayectoria biográfica específicas. Las dimensiones sociales, están

\footnotetext{
${ }^{4}$ Entendemos por racionalidades las maneras específicas en que los marcos de sentido y los condicionantes socioestructurales se articulan en las prácticas de los agentes sociales.

${ }^{5}$ Se realizaron 27 entrevistas a un total de 15 sujetos, así como tres grupos de discusión: uno con jóvenes (menores de 30 años: GDI), otro con jóvenes adultos (de 30 a 45: GDII) y el tercero con adultos (de 46 en adelante: GDIII).
} 
constituidas por el conjunto de condiciones históricas, socioeconómicas y sociopolíticas en las que se va gestando esa experiencia y trayectoria. A partir de esta diferenciación, definimos los siguientes factores que nos han permitido ordenar y hacer comprensible esta diversidad:

- En primer lugar, los ejes que posibilitan establecer la posición en la estructura social (educación formal, nivel de ingresos, ocupación, situación laboral).

- En segundo lugar, el origen social de clase y la trayectoria biográfica posterior (ascendente, descendente, estable), que introducen un elemento dinámico en la consideración de la posición social y explican las representaciones y prácticas de los sujetos como situadas en un mapa complejo en el que las actitudes incorporadas por ellos no conforman algo unitario, sino un conjunto plural y heterogéneo generado en contextos de socialización (primaria/secundaria) diversos (Lahire, 1998).

- En tercer lugar, la edad, que constituye un elemento de extraordinaria importancia en la medida en que permite introducir en el análisis la ligazón entre los procesos históricos y la conformación de experiencias sociales muy diferentes. La vida de los sujetos entrevistados de mayor edad viene marcada por la experiencia de la represión, frecuentemente violenta, de la homosexualidad en el régimen franquista (Mirabet i Mullol, 2000; Fuentes, 2001). Por el contrario, la vida de los sujetos gays más jóvenes está marcada por los cambios de alcance que afectan a la configuración de una identidad colectiva y al surgimiento de la comunidad gay (Villaamil, 2005). De esta forma, se crean experiencias, estrategias de resistencia/adaptación y mundos de sentido marcadamente distintos, que presuponen la aparición de posibilidades de vida inimaginables hace apenas 15 años.

- En cuarto lugar, se debe tener presente el hecho (que no entramos a argumentar) de que los HSH desarrollan su vida en una sociedad normativamente heterosexual, en la cual las relaciones entre sujetos del mismo sexo continúan estando fuertemente estigmatizadas; ello tanto en el sentido de actividades concretas desarrolladas en entornos 'no marcados' (heterosexuales), en los que se hace imprescindible un manejo estratégico del estigma, como en el sentido de elaboración de la propia identidad, subjetiva y colectiva, con relación a unas representaciones hegemónicas que deslegitiman la homosexualidad. Ese es el motivo por el que deben distinguirse diferentes estrategias de relación con la normatividad heterosexual y masculinista.

- En quinto lugar, y ligado con lo anterior, los sujetos no viven su sexualidad al margen de instituciones, modos de sociabilidad, valores y sentidos grupales. Para entender los diferentes modos de ser (homosexual, gay, hombre que tiene sexo con hombres...), es necesario - entonces- tomar en consideración los grupos con los que el sujeto interactúa y se identifica, y también la representación colectiva con la que dialoga para construir su identidad, bien por contraposición bien por identificación. No es lo mismo vivir la homosexualidad a partir de la identificación con un grupo con el que se comparte un estilo de vida que a partir del aislamiento, como tampoco es lo mismo que la representación colectiva del grupo que sirve de referencia 
sea la 'comunidad gay' o el de los usuarios de la prostitución. Por ello hablamos de modalidades de ser gay o estrategias de manejo de la afiliación al grupo.

A partir de los criterios señalados, tratamos de comprender las representaciones y prácticas de los HSH distinguiendo cinco tipos de racionalidad a la hora de afrontar el riesgo de exposición al VIH en las prácticas sexuales (preventivista, gay, de los aislados, de la confianza y de los supervivientes), de los cuales expondremos aquí solamente dos: la racionalidad preventivista y la racionalidad gay, la primera considerada "no-problemática" desde el punto de vista sanitario, a diferencia de la segunda ${ }^{6}$. Sin embargo, ambas requieren una explicación desde una perspectiva sociocultural, es decir, una explicitación de las condiciones y los condicionamientos sociales, culturales, económicos y políticos en los que se generan y dentro de los cuales son más probables.

Antes de exponer las dos racionalidades mencionadas, tal vez no esté de más recalcar que los resultados que presentamos a continuación se desprenden de una investigación más amplia acerca de las construcciones de riesgo y la prueba del $\mathrm{VIH}$ entre los $\mathrm{HSH}$, que se viene desarrollando en dos fases. La primera fase, ya concluida, responde a un estudio etnográfico convencional, en el sentido de que fue concebido y realizado por el equipo investigador ${ }^{7}$ empleando sobre todo técnicas cualitativas de investigación, tales como los grupos de discusión, las entrevistas en profundidad y el seguimiento de casos. En esta etapa, los intereses de la investigación se centraron, en primer lugar, en conocer las prácticas y representaciones sobre la prueba del VIH, que - bajo nuestra perspectiva - resultan incomprensibles sin considerar sus interrelaciones con las prácticas y representaciones sobre la prevención, el riesgo y la seropositividad (de ahí que estos cuatro aspectos articulen la exposición de las racionalidades que emprendemos en el siguiente epígrafe); en segundo lugar, las imágenes sobre la seropositividad, enfocada ésta, por un lado, como proyección de la propia vida en el supuesto de resultar uno mismo seropositivo y, por otro lado, como horizonte de experiencias sociosexuales; $y$, en tercer lugar, las formas específicas en que las representaciones sobre el cuerpo y los fluidos corporales se relacionan con la prevención del VIH. En la segunda fase, actualmente en curso, se han incorporado al equipo de investigación técnicos de salud de dos organizaciones gays, así como un miembro del Instituto de Salud Pública de la Comunidad de Madrid (responsable de la política preventiva con relación a los $\mathrm{HSH}$ ), con lo que la investigación etnográfica ha incorporado

\footnotetext{
${ }^{6}$ La imposibilidad de exponer con detalle cada una de las cinco racionalidades identificadas en nuestro estudio nos ha llevado a describir aquí únicamente dos de ellas, precisamente aquellas que, como se adelantó en la Introducción, presentan mayores contrastes en cuanto a las prácticas y representaciones en torno al riesgo, la prevención y la prueba del VIH.

${ }^{7}$ Del que, además de los autores de este artículo, formó parte la antropóloga social Débora Betrisey, quien participó principalmente en llevar a cabo las entrevistas.
} 
algunos componentes de los modelos de investigación-acción-participativa. El objetivo principal consiste ahora en estudiar los locales de sexo anónimo (LSA) entendidos como instituciones gays, es decir, como espacios en los que se da una alta concentración de interacciones sociales y sexuales entre HSH fuertemente normativizadas y formalizadas, y que pueden ser abordados no sólo como lugares en los que se practica sexo de riesgo, sino también como espacios privilegiados para la prevención del VIH/SIDA. La finalidad práctica se orienta en estos momentos a encontrar claves para la intervención preventiva de naturaleza grupal a través de estos espacios, añadiéndose nuevos instrumentos de investigación, tales como la observación directa en los LSA (parques, cuartos oscuros, saunas, clubs de sexo, etc.), en reuniones de empresarios/gerentes de los mismos (convocadas expresamente para el estudio) y la autoobservación de las sesiones de trabajo conjunto de los miembros del actual equipo de investigación.

\section{RACIONALIDAD PREVENTIVISTA}

Procedentes de medios de clase obrera, y con trabajos temporales y precarios, estos sujetos actualmente ocupan posiciones de clase media y media baja. Tienen experiencia y expectativas de movilidad social ascendente. Jóvenes o muy jóvenes, han crecido y/o tenido sus primeras relaciones sexuales siendo la epidemia de VIH y las campañas de prevención una presencia habitual. Incluimos aquí a dos jóvenes que ejercen ocasionalmente la prostitución, ya que comparten con los demás caracterizados por esta racionalidad, aparte de los rasgos señalados, una vivencia de la prevención del VIH en la que las medidas de sexo más seguro se encuentran ligadas a sus estrategias de construcción identitaria, en cuanto legitiman la sexualidad gay y revierten el estigma que pesa sobre ella ${ }^{8}$.

Mantienen una estrategia de relación con la sociedad normativa de alta visibilidad de la identidad homosexual, que es vivenciada como conquista frente a un medio familiar en el que la vigilancia de la identidad sexual es estrecha.

A la familia, (era necesario) que se lo dijera a todos, porque al fin y al cabo mis padres son mis padres, y más o menos estaban ya muy preocupados. $\mathrm{Y}$ (yo) estaba un poquito harto de que siempre me preguntaran por la novia: “¿Novia para cuándo?”(...)Yo le dije: “Mira, mamá, que soy homosexual", y a ella lo primero que le vino a la cabeza es que yo iba a ser travesti o iba a ser transexual o, si no, que iba a salir con un traje o... No sé, algo así muy básico (...) Porque no pueden vivir engañados, no pueden vivir así. (Jaime $1^{9}$ )

\footnotetext{
${ }^{8}$ Explícitamente señalamos que no es posible ni adecuado generalizar las conclusiones que se refieren a continuación al conjunto del colectivo de varones que ejercen la prostitución.

${ }^{9}$ Los nombres son ficticios. El dígito que, en los verbatims, aparece tras el nombre del entrevistado indica el orden de las entrevistas realizadas a un mismo sujeto (1: primera; 2: segunda; 3: tercera). Estas entrevistas se llevaron a cabo entre julio de 2003 y enero de 2004.
} 
Mi autoaceptación sexual fue terrible porque nadie de mi familia me comprendía, ni siquiera mis hermanas (...) Fue un proceso muy, muy duro. ¡Tú imagínate!, sin el apoyo de nadie de tu familia, de nadie, y el llevarlo todo así como a lo escondido, eso debe ser muy fuerte, ¿sabes?... Mis padres empezaban a notar como unas tendencias que tenía yo, (que) no me echaba novia, no hablaba de chicas, me vestía de una forma que a ellos no les gustaba, porque mi padre ha sido policía y es de los hombres muy, muy estrictos, ¿no?. Bueno, pues, a los dieciocho, casi diecinueve años, me pillaron con un chico y, bueno, pues, aquello fue la cruz, porque a raíz de eso me echaron de casa, y me tuve que buscar la vida (...) Yo no he contado con el apoyo de mis padres (José 1)

Se caracterizan por una concepción de la vida como lucha individual, que se corresponde con una trayectoria biográfica en la que han confrontado y superado obstáculos muy reales. Su visión del mundo posee un fuerte carácter individualista, casi darwinista.

Hoy en día ya todo está solucionado, sobre todo al tener la independencia mía total, y al ver que he llegado en este nivel en la vida, de hacer una carrera yo solo, y de tener un trabajo, yo solo, sin depender de nadie, que nadie me ha hecho este favor.

[Hablando de la gente a la que admira] Gente que tiene una meta para conseguir el dinero y para una ayuda o para ayuda de tu familia, o para sacar algo de ahorro y puedas invertir, pero si tú lo tienes solamente para la rumba (la juerga), para la discoteca, para la droga, para comprarte ropa de marcas y todo eso, te quedarás ahí toda la vida, en ese trabajo. Estoy satisfecho, porque estoy consiguiendo lo que yo quiero, que es ayudar a mi familia y salir adelante. (Ezequiel)

En estos agentes sociales apreciamos que la trayectoria ascendente que han experimentado les ha llevado a sustituir su rechazo inicial de (o, mejor, incomodidad con) las prácticas gays del ambiente, por una ambivalencia no ajena a su aspiración de formar parte integral del mismo, acompañada, eso sí, del reconocimiento (no siempre explícito ni consciente) de que carecen de las marcas de distinción, aptitudes y actitudes para conseguirlo. De igual modo, la consolidación de una carrera ascendente, aun cuando se parta de niveles bajos, puede llegar a adquirir en ellos prioridad sobre otros aspectos de la vida del sujeto, reforzando el mencionado individualismo.

Yo acabé allí [en su pueblo de origen] mis estudios, hice la mili y, una vez acabados, pues, ya vi que todo se había acabado allí. (...) Entonces, decidí... porque, claro, yo quería más, porque no tenía nada. Y por eso me fui de alli. Me fui a $\mathrm{C}$ [otro pueblo] pensando que sí, pero igual de mal. Entonces, me quedé igual. $Y$ de ahí me vine aquí ya [a Madrid] (...) Otra vez he empezado a hacer cosas de nuevo. Por ejemplo, me saqué un curso de [titulación media]. Empecé a hacer un curso también de actor de doblaje. Muchas cosillas que alli no... y que, claro, yo con Madrid estoy muy contento. (Jaime 1) 
La pareja adquiere una relevancia fundamental en este colectivo, más como aspiración que como reflejo de una biografia; relativizada, sin embargo, por el individualismo de base. Aquélla es tanto más importante cuando no se tiene otra red social, pero se subordina también a las estrategias de ascenso social.

Yo reconozco que teniendo pareja como que me desatiendo más de mí y que ocupa más la pareja, ¿sabes?, a nivel de estudios, a nivel de cursos, a nivel de moverte, a nivel de conocer gente... Y todo eso se puede (conseguir) con la pareja, pero ya tienes una vida muy limitada. (Jaime 2)

Se valora la conquista de la propia sexualidad en la construcción identitaria. Ello se hace no tanto desde la identificación con un grupo ("nosotros, los gays") como desde posiciones que se sitúan en la periferia del grupo de referencia, y que son doblemente periféricas en el caso de los prostitutos. Así, en su comprensión de la diferencia en razón de la orientación sexual es central el significante de "persona" como recurso para trascender la diferencia, como aquella categoría con relación a la cual puede ser concebida una equivalencia simbólica de las diferentes orientaciones sexuales.

No creo que sea algo de que una persona... Es que no creo que haya ninguna diferencia entre una persona y otra, ¿entiendes?. (...) Los homosexuales tienden mucho a reivindicar que son homosexuales, y mientras más homosexual soy, más maricón soy, ¿no?, en el sentido de que más buche (sic) llevo, camisas más apretadas llevo, más de todo llevo. (Jaime 1)

Frecuentan las instituciones del ambiente gay, y su forma de entrar en contacto con otros homosexuales, con fines sexuales o no, se centra en los lugares de intercambio sexual; ello a pesar de que poseen una imagen fuertemente negativa del ambiente, en especial de los modos de relación que se identifican como propios de él. Sus críticas se dirigen a ciertas formas de socialización - la pluma, relaciones sexuales anónimas, etc.-:

Aquí la gente va mucho a lo suyo. Se cree muy especial, ¿no?. Eso es lo que les pasa. Se creen especiales, se creen tocados por la gracia divina; algunos, ¿no? Mucho narcisismo hay por aquí, y eso a veces, pues...Uno va a la discoteca, y lo nota en las caras de la gente, lo nota en la actitud de la gente, lo nota en la forma de moverse de la gente: que son todos muy independientes unos de otros, cuando no entiendo por qué, cuando todo el mundo está buscando a otra persona (...) Y eso es lo que veo yo aquí: (gentes que se creen) reinas, cuando yo creo que son almas en pena. (...) $Y$ así no se va a ningún lado. Eso es lo que yo veo: mucha gente que no te ofrece nada, que ya no te aporta nada. Simplemente te llega, te conoce, te dice lo que tú quieres oír para que tú les digas lo que ellos quieren oír, y ahí se queda todo. (Jaime 1) 
En el ambiente gay, hay discotecas, bares, pubs... mmm, apariencias, falsedad, claro, promiscuidad también, o maldad. A mí el ambiente es una palabra que no me gusta. [E: ¿Y conoces los cuartos oscuros, la saunas...?] No; he estado alguna vez, como creo que todo el mundo, para saber lo que es (...) He estado en un cuarto oscuro, me he enrollado con un chico, pero vi que después del rollo, pues, que no sentías nada. (José 2)

Es muy superficial, más bien es de animal, de animales, para desahogarse y punto. (José 1)

Entendemos que esta ambivalente actitud se entiende -como hemos indicadotanto a partir de su aspiración a ser parte de ese ambiente, como del hecho de que esa aspiración sea permanentemente frustrada. De alguna manera, desean valorar su diferencia respecto a la identidad gay tal como ésta es percibida, y existen razones para pensar que captan que los rasgos de su modo de concebir el mundo y comportarse (que se derivan de su origen de clase) van a ser vistos como carencia desde la identidad gay central. De ahí el fuerte individualismo de su discurso, explicable - como decíamos- desde una concepción de uno mismo como conquista, como producto de un trabajo propio y personal. La voluntad es concebida como motor fundamental de la acción.

Todo este contexto es el que permite entender - desde nuestra perspectiva- sus actitudes ante la prevención, la sexualidad, el riesgo y la prueba. Con relación a la prevención, manifiestan ser consistentemente seguros. Incorporan un discurso preventivista en una versión particular, que gira en torno a la idea de protección y encaja bien en sus perspectivas sobre las cosas centradas en la voluntad y el esfuerzo. Las nociones de responsabilidad y rutina desempeñan un papel estructurante en la prevención.

Para mí la vida es rutina, en el sentido de que ya lo automatizo todo. Entonces, si me tengo que levantar para ir a trabajar de ocho y media a tres, sé que lo tengo que hacer todos los días (..)Va dentro de mi responsabilidad, pues, lo hago todos los días. Entonces, eso es lo mismo que ponerse un condón, eso es lo mismo que comer, es lo mismo que lavarse los dientes después. (Pablo, GDII)

Fíjate que yo ya estoy acostumbrado al condón. Yo no sé ya qué se sentirá al follar sin condón, porque es que ya no lo sé. (...) También con mi pareja, o sea, por ser mi pareja ¿lo voy a hacer sin condón?; no, siempre con preservativo, o sea, que yo eso lo tengo muy claro, que para estar enrollado, sea por vicio o por dinero, uno se tiene que proteger igualmente, igualmente, porque los riesgos son iguales, son iguales (Ezequiel)

Si tú no desconfias de mí, yo sí que desconfio de ti (...). Además, para mis exparejas, era una cosa como beber agua; el ponerse el preservativo enseguida era una cosa automática. (José 2) 
Obsérvese en las siguientes citas la deslegitimación del sexo no protegido que tiene lugar a partir del hecho real o hipotético de no asumir las propias responsabilidades:

Yo creo que el problema no viene con las relaciones esporádicas, con gente que no conoces, porque evidentemente hay que usarlo, no queda más remedio; no conoces a la persona y es tu responsabilidad (Jacobo, GDII)

Es que son unos viciosos e ignorantes, y te aseguro que la mayoría de ésos no utilizan preservativo, te lo aseguro, lo digo por experiencia. (Son) niñatos, niñatos irresponsables de ésos que van así al sexo a saco. Ésos te harían de todo; y lo triste sería que te pegasen alguna enfermedad y que al día siguiente te ven en la discoteca y ni te saludan. (José 2)

La sexualidad respetable y legitimada es la que se realiza siempre, en toda circunstancia, con preservativo, incluso dentro de la pareja. Desde cierto punto de vista, José y Ezequiel, prostitutos, llevan a sus extremos la lógica de identificar sexo legítimo y sexo protegido. José, que se identifica más bien como masajista y ejerce la prostitución sólo esporádicamente (de hecho, la deja de ejercer tras la segunda entrevista que se le realiza), emplea una serie de estrategias para proteger su autoimagen y salvaguardar su identidad frente al estigma: no sólo sobre la sexualidad homosexual, sino también sobre la sexualidad mercenaria: elige él a sus clientes, niega disfrutar con ellos, aduce tener exclusivamente razones económicas para ejercer la prostitución como modo de distinguirse de otros prostitutos, reserva ciertas prácticas, como la penetración, para sus parejas y, sobre todo, practica la prevención de un modo sistemático y exhaustivo.

Por su parte, Ezequiel comparte con José y con el resto de los sujetos preventivistas un apego estricto a las prácticas más seguras. Sin embargo, lleva ejerciendo la prostitución por un periodo mucho más largo que José, y aunque afirma tener intención de abandonarla, establece un plazo laxo. Ve el ejercicio de la prostitución desde un paradigma de profesionalidad, en el sentido de actividades circunscritas que no parecen afectar a su identidad social en su conjunto. A diferencia de José, utiliza con más naturalidad un lenguaje relacionado con lo laboral (el negocio, el cliente...), no elige a sus clientes y no establece una diferencia tajante entre parejas y clientes en términos de disfrute o tipos de prácticas.

El riesgo es para todos ellos profundamente inaceptable, y quien lo corre en las relaciones sexuales, un irresponsable carente de voluntad, una auténtica figura de identificación a la contra.

Son personas sin límite. Una noche de desenfreno la gente no controla, y lo que suele pasar, ¡es que yo alucino con los comportamientos y cosas que te piden!. (Pablo, GDII) 
En estos sujetos se aprecia una coherencia sobredeterminada entre la protección de la identidad personal y la integridad de los límites del cuerpo. Ello, además, es coherente con su propia experiencia social solitaria: el cultivar y proteger su yo implica mantener un férreo control de los límites del cuerpo, simbolizados a través de la prevención del VIH. El riesgo se sitúa de esa manera más allá del campo de sentidos asociados a la salud, para pasar a formar parte también de la construcción del sí mismo en torno a las ideas de control, de amor propio o - como se ha repetido- de responsabilidad. El riesgo de contraer el VIH se concibe como controlable.

Pero aunque yo no lo sea (seropositivo), ya también es por dignidad y por tratar a la persona como persona, es decir, no (a las prácticas sexuales no seguras). ¡Yo qué sé! (...) la gente sí está pensando que si estás haciendo algo (pidiendo el uso del preservativo) es porque tienes algo (el virus del VIH), ¿no? A lo mejor el que lo tienes eres tú, el que se está intentando proteger soy yo de ti, a lo mejor no me fio de ti un pelo, pero si me lo estás diciendo a mí (no usar el preservativo), ¿qué le dirás al de al lado que te haga?. Entonces, claro, es una cadena ¿no? (Pablo, GDII)

[Exponiendo por qué exige el uso del preservativo cuando adopta "un rol sexual pasivo" en una sauna] Yo cuando estoy delante (en la relación sexual), estoy delante y no veo nada, nada más veo la pared. No sé. Yo tengo amigos que me han dicho que, por ejemplo, ellos se han dado cuenta de gente que se lo pone (el preservativo) y después se lo quita, ¿sabes?, y yo me lo creo. Entonces, claro, todo esto es precaución. (Jaime 2)

La prueba es usada como una estrategia de prevención más, pero no tanto para confirmar el serostatus que, al no haber conductas de riesgo, no puede ser más que negativo y, además, no se percibe como dudoso. Ha sido rutinizada con el fin de remarcar la incorporación de las prácticas de prevención y como confirmación de lo correcto de las propias estrategias preventivas. El hecho mismo de realizarse la prueba significa - en otro nivel - una identificación con un modelo de sexualidad gay segura frente al SIDA que, de alguna forma, es el epítome de la sexualidad aceptable. Mediando en un viejo debate, resultaría de ello un uso no adecuado de los recursos sanitarios en términos estrictamente médicos, pero sí en términos de salud pública más amplios, en la medida en que un resultado negativo tiende a reforzarles la voluntad de mantener prácticas seguras.

[La primera vez que me hice la prueba] tampoco sabía nada de lo que era el SIDA, pero lo que hice fue hacerla. Yo como que me hice adicto a hacérmela cada seis meses, y aquí me ves (José 1)

Pues de aquí a seis meses, siete meses me haré la prueba [E: ¿Te la haces siempre como un reloj?] Sí, sí, claro, sí, pero eso no quiere decir que lo haga porque arriesgo 
mi vida, o sea, porque igual con razón me la hago, ¿no?, pero para mí es como una costumbre. No es que cometa locuras para hacerla, pero para mí ya es una cosa sistemática; automáticamente la hago. Me gusta hacerlo (José 2)

Que es algo que debería ser lo mismo que las mamografías, lo mismo que irte al otorrino o al oculista al año, pues, oye, ¿por qué no ir a tal sitio cada $x$ tiempo, si eres de tendencia.., no homosexuales, sino de tendencia de para acá o para allá?. Se sabe que tú estás metido más o menos ahí en el ajo. (Jaime 1)

Tal como se representan la prueba, ésta se inserta además entre las prácticas que, en general, tienen que ver con el mantenimiento de un estado general saludable.

Fue ya aquí (en Madrid) realmente cuando empecé a tomármelo como algo ya más regular. No sólo por el hecho de sabẹ lo del VIH, sino también para saber cómo estoy del azúcar, cómo me estoy alimentado, cómo.., porque una analítica es una analítica, y al cuerpo de vez en cuando hay que escucharlo (...) Sí lo hago.., - más o menos-digo "Ya me toca". (Jaime 2)

La posibilidad de resultar seropositivos suscita en ellos (como, en cierta forma, es comprensible en gente tan luchadora) la imagen de nuevas tareas, relacionadas con la toma de medidas referidas a entrar en tratamiento médico (incorporando favorablemente las exigencias del tratamiento al repertorio preexistente de rutinas preventivas) y a readaptar sus relaciones sociales.

Ay, no sé [qué haría si le saliera positivo]. A luchar y a sobrevivir, ¡qué remedio!, ¿o no?(...) Mira, yo soy una persona con muchas ganas de vivir, ¿sabes?, soy muy fuerte,... y seguiría los tratamientos, me sometería a tratamientos. (José 1)

O sea, yo también lo hago [la prueba con regularidad] por saberlo, pero por la siguiente reacción mía, que tiene que ver con lo que es el tratamiento e incluso con pensar "Ya que estás infectado, no seas tan cabrón de infectar a más gente" (...)Y si (alguien) se la hace una vez al año, pues, muy bien. La cuestión no es que te la hagas, sino por qué te la haces, que sea para tratar eso. (Jaime 2)

Antes me asustaba (la posibilidad de ser seropositivo); ya no. Yo digo que ahora el que se muere de SIDA es porque quiere, porque yo creo que puedes durar muchos años, y puedes llevar una vida normal, cuidándote y protegiendo a otras personas ¿no?, es decir, no ir contagiando así... Antes era como un miedo, que se veía que el SIDA.., pero ahora no. Ahora hay muchos adelantos y gente que vive perfectamente con medicamentos. (Ezequiel)

Con respecto a la seropositividad, existe una idea conectada con la de control: si el cuerpo es una fortaleza inexpugnable para el VIH, la seropositividad depende 
de la voluntad del sujeto, de su capacidad de control, y el seropositivo en general no representa una amenaza particular. Desde este punto de vista, su percepción de las personas seropositivas está relativamente menos mistificada que en otros grupos (sobre todo, menos que entre los que responden a la racionalidad de los aislados, de la confianza y de los supervivientes, no descritas aquí).

Cuando voy a tener una relación ya doy por hecho que el preservativo va a estar ahí. Entonces, el hecho de preguntárselo, "si eres seropositivo", no tiene nada que ver, ¿no? Ahora, si me lo dice, mira, se agradece. Se agradece, pero no cambiaría en absoluto nada. La relación seguiría igual, porque por mucho que me lo diga (que no es seropostivo), pues... (Jaime 1)

Mira, yo he estado con una pareja seropositiva cinco años, y todas las prácticas que hicimos desde el principio (fueron seguras), porque él fue sincero y me lo comentó al primer dia. Aunque no me lo hubiese dicho, hubiese hecho con él sexo seguro, es decir, lo tenía claro. Pues, he hecho todo tipo de experiencia sexual, pero todo con condón, y yo la verdad es que de maravilla. Sí, es verdad que al principio a lo mejor en ese tiempo me pude obsesionar un poco por repetirme la prueba, pero ya no... yo ya me olvidé, porque digo " $i S i$ es que es absurdo que me pegue nada, si es que lo que estamos haciendo, es que es imposible y aparte lo estábamos haciendo con condón!"... (Pablo, GDII)

Con todo, resulta significativo que en su discurso, cuando se aborda el tema de la seropositividad, se aluda de forma espontánea a la existencia de un conjunto acotado de sujetos seropositivos en el que se encarnan comportamientos de contagio intencional y "perverso"10.

Y yo me quedo muy flipado, porque hay gente que ve, que ve, que ve (la posibilidad de contagio), pero no hace caso ninguno. $Y$ hay gente que, por ejemplo, lo tiene y ya que lo tiene, por qué no va a transmitirlo. Que es la gente que realmente miente y me preocupa, ¿no?, porque la gente que tenga miedo a transmitirlo, pues, oye, no, pero hay gente que lo transmite "porque yo lo tengo", porque son así. Y eso veo que está patente ahí (...) Hay mucha gente que le da igual, que le da igual todo. Le da igual tanto pillarlo como transmitirlo, ¿no? (Jaime 2)

\footnotetext{
${ }^{10} \mathrm{El}$ imaginario acerca de un origen absoluto y absolutamente maligno de la infección quedó fijado, en relatos periodísticos poco rigurosos de las investigaciones epidemiológicas iniciales, en la figura del 'paciente cero', recogida en And the bad played on de Randy Shilts (1987) y en la película homónima de R. Spottiswoode (1993). Generó críticas desde la propia epidemiología (Gmerk, 1989) y desde la reflexión de los movimientos gays: la película Zero Patience (1993) es, por ejemplo, una respuesta a los componentes más ideológicos de esta construcción. Tanto el discurso como el contradiscurso en torno al 'paciente cero' han permanecido activos, aunque en sectores distintos, como vemos del colectivo de HSH, y en el discurso oficial (Villaamil, 2005).
} 
R IS

REVISTA INTERNACIONAL DE SOCIOLOGÍA

№ 42, SEPTIEMBRE-DICIEMBRE, 2005

FERNANDO VILLAAMIL, MARÍA ISABEL JOCLLES y FERNANDO LORES

Cualquier comportamiento que ponga en peligro la salud tanto de sí mismo como del compañero sexual es - tal como ya se ha indicado- descalificado moralmente e interpretado como un acto de "locura", "descontrol" o falta de "responsabilidad". En este marco es en el que hay que entender la emergencia de ese discurso, en el que - por otro lado - no deja de ser reconocible un cierto "aire de familia" a partir de la reiteración de una representación fuertemente individualista de la existencia. En consecuencia, y dado que la pregunta sobre el estatus serológico del otro es el interrogante nunca explícitado, pero siempre pensado como posibilidad, lo que estos sujetos "irresponsables" parecen comprometer es una norma implícita según la cual, en caso de seropositividad, se tiene la obligación de comunicar el seroestatus al compañero sexual por una cuestión de "respeto" y reconocimiento de la "dignidad" de la "persona". En última instancia, lo que está en juego es una representación particular del individuo y la existencia social.

[E: ¿Tú tendrías relaciones con un seropositivo, sabiéndolo?] Yo tendría relaciones con un seropositivo sabiéndolo, pero... Es que nunca se me ha planteado, pero yo creo que sí las podría tener (...) Pero, oye, decir "Soy seropositivo" no es como decir "Soy pelirrojo" o "Soy moreno", ¿no?. Incumbe que le puede pasar (a él) algo, e incumbe que a ti te puede pasar algo (...) Pero, bueno, son cosas que, por lo menos, se debe informar (...) Es que todo se basa en el respeto. Si tú respetas a una persona, ni tienes por qué preguntarle si es seropositiva ni tú tienes por qué ponerte en ninguna situación de riesgo (...) Lo que sí reconozco que haya mucha gente que se eche para atrás en estas cosas [E: Claro, quizá eso también está incidiendo en que se diga tan poco, ¿no?, en que no se diga ni a los amigos, como comentabas antes] Sí, pero a mí me da mucho miedo, porque también hay mucha gente que se tapa en eso y no lo dice por miedo a qué dirá la gente, ¿no? Vale, puedes tener tus miedos, pero eso tiene que ser como otra salida del armario. La salida de decir "Mira, soy seropositivo"; y yo te puedo contar "Pues, bueno, yo tengo cáncer de pulmón", no tiene nada que ver una

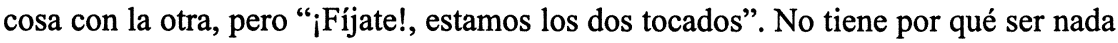
del otro mundo. (Jaime 1)

Este grupo, desde un punto de vista epidemiológico y de salud pública, no representa un problema, hasta el punto que podemos decir que sus integrantes han incorporado la prevención del VIH a su propia identidad, en términos de referente de sentido y de prácticas.

Existe una alta probabilidad de que llenen las charlas y los grupos de intervención, ya que se trata a veces de auténticos entusiastas de la prevención que no parecen tener nunca suficiente información. Con todo, es probable que requieran refuerzo, y que no sea inútil dárselo: los sujetos que sustentan esta racionalidad son, como los demás, inestables (algunos proceden de situaciones agrupadas como "racionalidad de los aislados"), y sospechamos que a largo plazo no pueden excluirse situaciones en las que haya depresión, o simplemente, desánimo. No 
queremos dejar de destacar que con una frecuencia sorprendente en una muestra tan reducida, los sujetos con esta racionalidad habían pasado por algún tipo de terapia psicológica, o abrazado alguna doctrina religiosa o afin, que no sabemos exactamente cómo calificar.

\section{RACIONALIDAD GAY (O GAY CENTRAL)}

La racionalidad que tratamos a continuación es manifestada por sujetos que se caracterizan por construir su identidad desde la identificación con el estilo de vida gay, lo que afecta a sus actitudes y percepciones. De procedencia de clase media y media alta, estos sujetos han cursado estudios superiores y sus expectativas son de mantener su estatus de clase. Pertenecen a generaciones relativamente diversas, con edades entre los 30 y los 50. El SIDA ha sido una presencia que era imposible ignorar a lo largo de toda o la mayor parte de su vida como gays.

Son posibles entre ellos, especialmente cuanto más jóvenes, estrategias de manejo de la visibilidad más complejas que las que subyacen en otras racionalidades, situándose entre el total ocultamiento a cualquiera que no esté en el círculo de amistades gays, y la visibilidad de la identidad social y sexual en la totalidad de sus actividades. Además, estas estrategias pueden cambiar con el tiempo.

Me casé. Que me casé por ayudar a una amiga, no por querer una apariencia normal. Por amor me casé, pero no por crear una apariencia falsa en el colegio [religioso en el que trabaja], de armarizado. Los curas, lo peor.(...) Yo no puedo trabajar más en un sitio de curas (...) Que J. (un amigo suyo) se pone muy histérico (ante el hecho de que el entrevistado trabaje en un colegio religioso). Prefiero no ser tan histérico, (...) yo creo que hay que ser más sutiles, como ellos, y hacerles la guerra de una forma más sutil. Y yo la forma que tengo ahora (de hacer esa "guerra") es educando a los niños, mostrándoles un poco lo contrario de lo que les enseñan los curas. (Arturo 1)

Ello se explica dentro de un contexto de necesidades del sujeto a la hora de garantizar su reproducción social: con expectativas de llegar a ser cuadros medios y superiores, diversifican sus estrategias de visibilidad en función de necesidades de acumular capital educativo (estudios superiores, masters, etc), capital social y/o capital económico (hasta qué punto el mantener un nivel de ingresos depende o bien de la familia o bien de un entorno laboral que demanda heterosexuales o desanima activamente hacer pública la propia orientación sexual). Con relación a esto mismo, nos encontramos con diversas valoraciones de la necesidad de 'salir del armario', pero en todo caso no sentida como algo imperioso, sino más bien negociable.

Bueno, mi familia no lo sabe, quiero decir, mis padres no lo saben, jeh! Una de mis hermanas lo sabe y la otra no... Quiero decir, igual sí lo saben (sus padres). Yo no he 
RIS

REVISTA INTERNACIONAL DE SOCIOLOGía

№ 42, SEPTIEMBRE-DICIEMBRE, 2005

FERNANDO VILLAAMIL, MARÍA ISABEL JOCILES y FERNANDO LORES

hablado con ellos del tema (...) Antes lo que tenía era miedo; ahora lo que me da es pereza, ¿sabes? [Es] un poco como que no quiero decir nada porque es que no creo que tenga que decir nada... Por mi planteamiento de vida, ahora no me cuestiono o me surge la necesidad, a lo mejor, de tener que decirlo. (...)Yo creo que conozco a mis padres y tal, y creo que ellos no serían (de) aquellos que me echarían de casa o me rechazarían. Es decir, su trato conmigo seguiría siendo el mismo, pero por su forma de ver las cosas y por comentarios que hacen, internamente creo que no lo encajarían; es decir, son ya mayores, tienen su forma de ver la vida, ¿no?, y cambiar los planteamientos a gente así, pues, es difícil, ¿no?(...)Y es lo que te digo, es decir, yo no creo que esté ocultando nada. A mí hasta ahora no me han preguntado nada... En el momento que me pregunten, yo contestaré... (Felipe 1)

Para el modo en que construyen su identidad, resultan mucho más cruciales los significados compartidos que connotan comunidad y diferencia, que son nucleares en su autopercepción. La identidad personal y colectiva es construida mediante una identificación con un grupo de iguales gays que tiene un papel importante en sus vidas. Esta identificación se realiza en términos reales, de personas con las que se relacionan y sitios que frecuentan, pero también a partir de una comunidad imaginaria, de un "nosotros, los gays", que aparece con naturalidad en su discurso y que lo regula (a diferencia del "ellos, los gays" presente en otras racionalidades).

Sí, sí que lo frecuento [el ambiente gay]. Vamos, yo normalmente..., mi sitio habitual de salir con mis amigos y tal sí es Chueca. Y sí que salgo por alli y tal. (..) Es un poco como la contradicción: de una parte, sí, hay cierta incomodidad al tema de que sea como un guetto; es decir, somos nosotros, nuestra música, nuestras bromas... y iya está!, y estamos aislados del resto del mundo. 'Pero, joder, ¡si es que estamos viviendo en un mundo...!'. Ese tipo de cosas. Y, por otra parte, también (está) el hecho de que como las cosas todavía no están bien y uno no puede ir tranquilamente por algunos sitios o hablar tranquilamente con determinadas personas... (Felipe 1)

Vivimos en esta jaula fucsia, maravillosa, donde las copas son más caras pero, más o menos, nos dejan vivir, ¿no? (...) La mayoría de la gente no vive en esas circunstancias. (Roberto, GDII)

La voluntad como motor de la acción pasa a un segundo término frente a un otro generalizado gay y normativo que legitima o deslegitima ciertas prácticas. La identificación con la comunidad gay implica una socialización secundaria que incluye numerosos aspectos de la identidad social. Conviene destacar que uno de estos aspectos es la actitud ante la experimentación sexual, lo que se muestra en una cierta afectada naturalidad al hablar de la propia sexualidad, de un modo que en contextos en los que no se comparten esos valores resultarían chocantes: 
Guarreaba, de esas cosas del guarrear. Me acuerdo que me dijo '¿te gustaria que te metiera el puño?'; y yo, 'ay, pues, inténtalo'. Él tenía una mano muy pequeña, así que 'ay, pues, inténtalo'. Pero, claro, así a palo seco no puede ser. Él tenía experiencia, pero yo, hija, poca. Y luego, pues, la lluvia dorada, que siempre viene bien practicarla de vez en cuando, ¿no? Salivazos...[E: ¿Te meaba él a ti?] Me meó él. ¡Ay, me encantó! Es una cosa que hay que reivindicarla. (Arturo 2)

El discurso de la prevención se reconoce como importante y válido, y se le concede autoridad aunque de un modo ambiguo, como enseguida veremos. Nos hemos encontrado con que si bien mantienen comúnmente prácticas seguras, éstas se ven salpicadas de forma más o menos frecuente por prácticas de riesgo. En marcado contraste con otras racionalidades (especialmente, la preventivista), las prácticas de riesgo no son elaboradas como algo aborrecible o inconcebible, que sitúa al sujeto fuera de la categoría de persona, sino - en alguna medida - aceptables. Así, la legitimidad y relevancia otorgadas al discurso preventivista no excluye una cierta relativización en función de circunstancias que no son contempladas en la información sobre prevención, pero que son relevantes para los sujetos.

[Últimamente] He tenido más prácticas de riesgo que todo el tiempo que he tenido miedo al (lema de que el) sexo con el sida era igual a morirse, porque yo he perdido amigos, como supongo que muchos aquí, ¿sabes? Es decir, que pasa el tiempo, encima te haces más mayor, y sin embargo...[Roberto: más vicioso (risas)] bajas la guardia, bajas la guardia, claro. [Juan: Ahí, ahí; ésa es la palabra] ¿Por qué? Porque muchas veces también es para justificarse mejor las barbaridades que haces. (Alfredo, GDII)

De todas maneras yo soy una persona un poco rara, y a mí me importa un carajo todo, entre comillas. [Murmullos] ¡No!, entre comillas (...) No soy nada hipocondríaco, y no sé, me importa tres... Si me pasa algo bueno, lo disfruto; si me pasa algo malo, pues, mira, o sea que no me hundo [Carlos: Sí, pero que no te pase, mejor, ¿no?] Sí, pero que tampoco estoy con la paranoia de, vamos, 'no me toco la pilila sin condón', ipues no! Es que... [Juan: Es que es un poco paranoia] Sí, hay excesos, pero hay gente que peca de mucho, de mucho cuidado. Yo, a lo mejor, peco de poco... (Mateo, GDII)

Si tenemos que prevenir..., o sea, no comemos pollo, por lo que pasa con lo de los pollos (se refiere a la epidemia aviar asiática), cuando la carne, por lo que pasó con la carne (se refiere al problema de "las vacas locas”), ¡eh!... Mira, desde que existe el VIH, si todos pensáramos como piensas tú, nos envolveríamos en papel de éste transparente, y nos iríamos a una sauna a echar un polvo pero diciendo 'Chist, ¡ni abras el agujero!' (Ernesto, GDIII)

Siempre hay alguien que aunque tenga ese cuidado, siempre hay un momento en el que se pasa, un día, o un momento, ¿no?, es decir, que uno no es estable tampoco en sus decisiones continuamente... (Miguel, GDIII) 
RIS

REVISTA INTERNACIONAL DE SOCIOLOCIA

№ 42, SEPTIEMBRE-DICIEMBRE, 2005

FERNANDO VILLAAMIL, MARÍA ISABEL JOCILES y FERNANDO LORES

El riesgo forma parte, en general, de la vida de estos sujetos, siendo el exponerse al VIH contemplado de forma más o menos consciente como imponderable no deseado, pero asumible, de una vida gay comme il faut; recordemos que reconocen como válidos los mensajes preventivos, lo que deriva en un discurso en cierta forma ambiguo.

Para mí, los que estamos dentro del rollo gay de una manera o de otra, con cierta conciencia, probablemente con prácticas de todo tipo, algunas de riesgo,.. pero los que llevan doble vida, los que no se auto-aceptan, los que no sé qué, ésos son generalmente, o los que me he encontrado yo, por lo menos los que hacen, vamos, el Sexo Inseguro en mayúsculas. (Roberto, GD II.)

A lo mejor lo que me apetece es que no se tenga que cortar nada, ¿no? (...) Estoy haciendo algo mal, pero qué gustazo da. (...) Fíjate, el último gran polvazo que me eché en la playa, me eché un polvazo fantástico, supe parar y ... ¡Joder, si es que si se hace todo bien...! Es este elemento de peligro, ¿no?De peligro y luego como de autocastigo. No sé. (Arturo 1)

Entendemos que el riesgo es sacado de un contexto de sentidos asociados a la salud o a la defensa del cuerpo, que es donde lo ubican los discursos preventivistas, y percibido como situado dentro del contexto del placer y la experimentación con la sexualidad.

Yo creo que es un poco mezcla del vicio que tiene la gente, que es abismal. $O$ sea, yo mismo reconozco que cuando salí del armario era un tío super-clasicón, tal-tal-tal: 'A mí sólo me gusta eso'. Y ya con el tiempo (...) veo que necesito hacer más cosas y más cosas y más, o sea, hacer más variedad. Y cuando metes más variedad, (...) también hay posibilidad de que metas más riesgo, [Alfredo: uhum - asiente-] porque no te vale ya sólo el tití-tutú, y jala!...En fin, yo veo a la gente haciendo unas cosas (que son) de decir 'Bueno, si esto es lo que te satisface, pues, bien, pero a mí como que no (me satisface)'. (Juan, GDII)

La experimentación es, en este sentido, parte de la cultura sexual gay en la que han recibido una socialización o enculturación secundaria, como señalamos arriba. Así, puede tener un importante papel como elemento capaz de producir un sentimiento de afiliación simbólica al grupo y, por tanto, ser aceptable. Obsérvese a continuación cómo Felipe se identifica con un nosotros promiscuo e incluso hace una cierta defensa, desde su 'círculo gay', de la promiscuidad, algo impensable para otros sujetos.

Donde yo me muevo son círculos gay; entonces, es verdad que en el mundo gay la gente es muy promiscua, y es verdad, pero es una cosa como que a los gay nos 
ofende mucho el decir 'es que [somos promiscuos]'..., pero es verdad. Los gay que tienen sus parejas y tal, pues, sí... pero ¿yo que sé?, los que no tenemos pareja somos muy promiscuos, y mucha gente que tiene pareja puede ser muy promiscua también, ¿sabes? (Felipe 2)

Las razones aducidas para justificar las prácticas de riesgo son múltiples: hartazgo del sexo seguro, el efecto de las drogas y el alcohol, la relajación por las terapias antirretrovirales, ser la parte insertiva en la penetración, penetración sin eyaculación, tener baja la autoestima, ruptura de pareja, estar en depresión, no disponibilidad del preservativo, el calor del momento y las cualidades de la pareja... Tomadas literalmente, podrían verse como meras racionalizaciones a posteriori de sus prácticas. Con todo, si bien entendemos que estas razones no están en el origen de las prácticas de riesgo, sí pueden tener ciertamente - dado el caso- un peso a la hora de inclinar la balanza del lado de la asunción del riesgo, pero como factores coadyuvantes. En este sentido son importantes, aunque no pueden explicar esas prácticas por sí mismos. En definitiva, frente a esa 'oficialidad' del discurso preventivista generado por las instituciones, para estos sujetos las prácticas de riesgo pueden ser un elemento de identificación grupal.

$\mathrm{La}$ ansiedad que provoca la prueba del $V I H$ proviene del miedo tanto a la enfermedad, que es conocida de primera mano, como al ostracismo que puede venir aparejado con ella. Pero en estos casos hay que añadir, además, el peso del miedo a perder las condiciones para mantener un determinado estilo de vida, el miedo a la dependencia.

[E: ¿Te da miedo la posibilidad de ser seropositivo?] Yo creo que sí. Sí, sí. ¿Miedo? Sí, yo creo que sí. No sé si miedo a la muerte, ¿no? Es el miedo a la muerte, no sé, a lo que puede ser el estigma social, que ya no es tan estigma, ¿no?, a cómo pueden cambiar tus relaciones con la familia, para bien o para mal, pero...verte desvalido, necesitado. Sí, me da miedo [E: ¿Desvalido?] Desvalido, necesitado otra vez del calor familiar, ¿no? Y todo esto. (Arturo 1)

Sin embargo, en el discurso grupal que se constituye en dominante, el miedo no parece ser un motivo legítimo para no realizársela.

Juan.- Tú mismo dices que a ti te da un poco igual (un resultado positivo en la prueba), [entonces] ¿por qué no te la haces?

Mateo.- Me da un poco igual, pero porque...

Juan.- Evidentemente no te va a dar igual. Aunque soluciones la papeleta, está claro que no te va a dar igual, pero, bueno, a lo mejor no te lo tomarías tan a la tremenda. Yo creo que a mí me pasaría un caso por el estilo. Me jodería bastante, pero no me pondría a llorar, las cosas se solucionarían...

Mateo.- Yo soy el que más hincapié ha hecho en que ojalá se la haga todo el mundo 
y que sea obligatorio...

Juan.- Pero, bueno, precisamente por eso, háztela y quédate todavía más tranquilo, ¿no?

Mateo.- Es que yo ya te estoy diciendo que estoy muy tranquilo.

Juan.- Pues, quédate todavía más

(Mateo y Juan, GDII)

Ello conlleva dos posicionamientos frente a la prueba. Por un lado, se rutiniza intercalada con prácticas de riesgo, puesto que el momento de hacerse la prueba del VIH no entraña habitualmente la intención de cesar en estas prácticas que, de manera ambigua, son valiosas para los sujetos. En cierta medida, se realiza porque existe una percepción de que es 'lo que hay que hacer'. Así, puede darse el caso de que llegue a ser utilizada de una forma indeseable desde un punto de vista preventivo, como mera confirmación de que se sigue siendo seronegativo entre prácticas de riesgo, siendo además difuso el límite entre el uso 'adecuado' e 'inadecuado' de la prueba. Llevado ésto al extremo, un resultado negativo cuando es probable uno positivo puede conducir al sujeto a una percepción de sí mismo como invulnerable al VIH (como "la prostitutas africanas", que aparecen en el discurso de Juan).

Yo no puedo estar con la duda, o sea, (cada) seis, siete meses me la hago y si algún día tiene que salir algo malo,jjódete y baila!, pero me la hago. (...) Y yo ¿qué quieres que te diga?, en fin, no suelo hacerlo sin condón pero, ufff, no sé, reconozco que en ese sentido no lo veo tan, $\tan , \tan$ dramáticamente como lo veía antes [de tener sexo sin preservativo durante un año con una pareja que resultó estar infectada]. Y si algún día lo cojo, pues, mira, evidentemente tendré que dejar de hacer el burro (...), pero es que después de ver esa experiencia de estar un año a diario...o sea, es que yo me quedé como diciendo "ipero bueno;". Pero, en fin, es eso, es una experiencia un poco heavy, pero a mí me ha hecho bajar un poco la guardia, porque es que veo que después de lo que he hecho, si no me han contagiado, ¿cómo coño se contagia uno?(...) No puedo evitar bajarla. (Juan, GDII)

Por otro lado, puesto que el miedo no es una actitud aceptable para el grupo, ello supone que algunos sujetos vivan el retraso del momento de hacerse la prueba de modo culpabilizado. A pesar de lo que cabría esperar, esa vivencia culpabilizada del retraso no se plasma necesariamente en una mayor motivación para hacérsela, sino que con frecuencia disuade de ello, sobre todo cuando más probable ha sido la exposición al VIH. En este sentido, aunque pueda resultar aventurado, nos atrevemos a afirmar que cuanto más probable es la exposición, mayor es el miedo y menor la predisposición a hacerse la prueba, y que esto es tanto más así cuanto más tiempo pasa.

Como una obligación (veo la prueba), sí, como una imposición de la autoridad, no sé. Lo veo un poco como diciendo: bueno, no sé, tampoco he hecho sexo muy..., 
he cometido alguna infracción, pero tampoco he tenido una vida de Mesalina, de Calígula..., promiscua. Y yo, por ahora, no sé, me da pavor, no sé, sí, me da pavor (el hacerse la prueba) (Arturo 1)

En todo caso, es preciso no perder de vista que estamos señalando paradas más o menos coherentes en un proceso que es más dinámico y que posee una dimensión temporal clara. No puede olvidarse que se trata de sujetos que se identifican con un colectivo al que se pertenece por socialización secundaria, por lo que indudablemente proceden de otras situaciones. Si en el pasado han experimentado una etapa de aislamiento, o han tenido relaciones con una pareja de la que desconocen su serostatus, es posible que a la altura de los 30-40 se encuentren con la necesidad de confrontarse con la posibilidad real de ser seropositivos.

En cuanto a la seropositividad, aunque no se excluye cierta ambigüedad ante la figura del seropositivo, ésta es habitual en el horizonte de experiencias de quienes sustentan esta racionalidad, lo que implica cierta familiaridad con la enfermedad y también su desdramatización.

Yo informaría realmente de las terapias que hay ahora, del tratamiento, que son - yo creo- bastante buenas, bastante reducidas, y la gente a lo mejor lo vería de otra manera. No sé, tú dices 'Tengo cáncer', y todo el mundo 'Ay, pobrecito', dices 'Tengo sida', y salen todos corriendo. Entonces, [Ernesto: Sí, sí...] lo que habría que cambiar es eso, que no sea una peste, y de esa manera yo creo que la gente se haria más la prueba. (Mateo, GDII)

Yo tenía amigos en el 95 que se estaban muriendo, o sea, que hoy en día están de puta madre. (...) En el año 94, 95, estaban cayendo como pollitos, y ahora la gente no. Y la gente que estaba fatal en aquella época está llevando (una vida) normal, a pastillazo limpio, pero... (Roberto, GDII)

La perspectiva de tener contactos sexuales con seropositivos también está mediada por una concepción de la sexualidad en la que la experimentación adquiere tanta o más relevancia que la propia prevención. Aunque, para estos sujetos, no resulte en absoluto indiferente el estatus serológico de la persona con la que mantienen relaciones, lo interesante es reparar en sus reacciones al enterarse del (o sospechar el) seroestatus positivo del compañero sexual cuando ello acaece en el mismo curso del encuentro, pues es entonces cuando se pone de manifiesto una definición de la situación que excluye su proyección hacia el futuro. A diferencia de lo que encontrábamos en el caso de los preventivistas, las disposiciones temporales parecen ahora organizarse, incluso en lo que atañe a relacionarse con seropositivos, en torno a las exigencias marcadas por el "momento" del encuentro sexual.

[E: ¿Has tenido relaciones sexuales con seropositivos?] Que yo sepa, no, y luego... con uno sí, ¡uhm!, con uno sí. [E:¿Y cómo fue?] (...) Con mucha prevención: no muy 
a gusto. Fue en el Retiro, y fue rápido, fue una paja rápida. Sí, yo, a lo mejor, por la cara, por el exceso de delgadez... por eso lo intuí. A lo mejor no, a lo mejor estaba haciendo una severa dieta: ¡Simón del Desierto subido en la columna!. [E: ¿Fue así (como lo supiste), por la impresión?, ¿tampoco lo sabes con seguridad?] Exacto. [E: Pero ¿te da reparo...?] Me da reparo, sí, sí. No sé, me da reparo, claro. Puede ser peligroso, ¿no? [E: ¿Y lo piensas alguna vez cuando te vas a enrollar con alguien?] No. No lo pienso. No. En este chico fue muy evidente, porque le vi. Él tenía algo que me atraía, pero era muy evidente, ¿no? (...) Sí, para no besarnos o.. ¡prejuicios míos!. Había algo en él que no me invitaba a besarle, pero le besé porque... me pasó el sabor a Ducados. (Arturo 1)

Quien pone en peligro de contagio del VIH a su partenaire por haber descuidado la confirmación de su propio seroestatus no es objeto de valoraciones morales planteadas en los mismos términos de la racionalidad preventivista ("falta de respeto", "ir contra la dignidad de la persona"...). Llama la atención, por ejemplo, que cuando narran casos en que han estado expuestos al VIH en relaciones con compañeros sexuales de los que desconocían previamente su seropositividad, los relatos sobre todo las vivencias de pánico que experimentaron y/o las reorientaciones de sus vidas que se plantearon a partir de entonces; lo reprobable no es tanto que no se dijera, sino que se mintiera al respecto y, sobre todo, que haya habido prácticas de riesgo sistemáticamente, lo cual sabemos como coloca fuera del grupo. A este respecto, se tiene la impresión de que sus juicios apelan menos a una quiebra de un orden moral abstracto que a una ruptura del normal desarrollo del juego social y sexual, de la norma grupal concreta. Ello puede estar ligado al hecho - ya señalado- de que, en los gays centrales, los preceptos de la norma preventivista entren con frecuencia en contradicción con la "norma vivida" y, de este modo, la primera (aunque aceptada como válida) vea mermada su capacidad de otorgar sentido a sus experiencias.

Yo tuve una pareja durante un año, y nosotros dejamos de utilizar el condón, pues, a las dos semanas, (y así) durante un año. Follamos como locos, tanto él a mí como yo a él, y corriéndonos dentro y todo ese rollo, sexo oral, o sea, todas las posturas que te puedas imaginar. Nos fuimos a hacer la prueba. Yo recogí los resultados, él no, porque no pudo, porque tal..., porque en el fondo tenía miedo (...) Bah, pasaron siete, ocho meses. Fui otra vez a hacerme la prueba, él vino conmigo, y cuando se fue a hacer por segunda vez la prueba resultó que el tío es seropositivo desde hace cuatro años; por lo menos, desde hace cuatro años. Y a mí cuando me lo dijo, dije "Ya está, Juan, ya está", dije "Ya has metido la pata, tío". Juro que soy negativo, y yo he follado con ese tío treinta mil veces de todo y no-me-lo-ha-pegado (...) Bueno, me hice la prueba, me la hice al mes, me la hice (de nuevo) a los tres meses, o sea, una paranoia, esos tres meses los he pasado peor que en mi puta vida.. [Carlos: ¿Y de eso cuánto tiempo hace?] Pues yo lo dejé con este chico hace año y medio o así. Por supuesto, después de aquello, aparte 
de otras cosas, dije "Mira, tío, yo lo siento mucho pero, por hijoputa..." [Alfredo: ¿Él lo sabía?] ¡Qué va!, no, no, no... [Alfredo: ¡Ah, si no lo sabía...!] No, no, pero es que, en fin, él me dijo que no había hecho unas cosas, que él jamás había hecho... ijoder!, y según después noticias, e incluso él me lo reconoció, que el tío había sido...' welcome to the party', o sea, entra y disfruta (Juan GDII).

Se entiende a partir de lo expuesto que consideremos llenos de limitaciones los planteamientos que insisten en la noción de proporcionar información, unidireccional y monológica. En primer lugar, hay que contar con que entre estos sujetos no existe percepción de sí mismos como parte de un grupo necesitado de prevención (algo que sale constantemente en los grupos de discusión), y además con la dificultad añadida de lanzar mensajes que capten la atención de una población que se considera sobradamente informada. Más aún, en relación con las intervenciones dirigidas al cambio en las actitudes ante las prácticas de riesgo, parece preferible centrarlas en buscar modos de desligar experimentación sexual y exposición a riesgos. Un abordaje con posibilidades de éxito partiría de confrontar a estos sujetos con la posibilidad de que hayan erotizado las prácticas no seguras, puesto que ello forma parte de los sentidos compartidos que no se explicitan. Los mensajes que se dirijan a este grupo deben compartir el alto valor dado por ellos a una vivencia de la sexualidad no convencional, pero que desde su propia perspectiva forma parte de las prácticas que los identifican, y que sobre todo no están necesariamente reñidas con la prevención del VIH.

Una intervención que se proponga al tiempo promover la realización de la prueba y partir de una comprensión de la racionalidad particular que mueve a estos sujetos se articularía, en definitiva, a través de un espacio de diálogo en el que puedan separarse las diferentes circunstancias y procesos en los que se inserta la realización de la misma. Incidir en mensajes que refuercen la culpabilización del que retrasa la prueba, ignorando sus razones, puede resultar en disuadir y aislar a sujetos que viven esta situación ya desde la culpabilidad.

\section{CONCLUSIONES}

El modelo de análisis presentado tiene como finalidad servir para que los agentes sociales y las instituciones encargadas de intervenir con la población de HSH puedan reflexionar de un modo más incisivo sobre cómo modular sus mensajes y las prácticas de intervención en función de las personas que, aunque estén ante nosotros, a menudo representan un enigma a resolver. En este sentido, es necesario tener presente que describir los comportamientos en términos de una única racionalidad que se confronta con la irracionalidad de los comportamientos 
RIS

REVISTA INTERNACIONAL DE SOCIOLOGIA

№ 42, SEPTIEMBRE-DICIEMBRE, 2005

FERNANDO VILLAAMIL, MARÍA ISABEL JOCILES Y FERNANDO LORES

que no se ajustan a ella, puede ser un obstáculo para una cabal comprensión de los sujetos, imprescindible para desarrollar intervenciones realmente eficaces. Como comentábamos al principio: no existe una sola racionalidad, sino diferentes racionalidades (Calvez, 1996). Los sujetos sociales nunca se comportan según criterios de racionalidad definidos externamente siguiendo criterios exclusivamente técnicos. Abordar a los sujetos desde sus propios marcos de sentido y contextos sociales significa tener presentes los modos específicos de comprender las relaciones sociales, la sexualidad y el riesgo que están detrás de sus acciones, para captar realmente los porqués de sus decisiones. Vistas desde las propias perspectivas de los sujetos, sus prácticas y percepciones poseen una coherencia, que es a la que debe aproximarse la intervención.

Una línea de intervención que se fundamente exclusivamente en la transmisión de información perderá eficacia por mucho que esté fundamentada en una supuesta adaptación a necesidades, definidas de forma apriorística. Los sujetos incorporan los mensajes de prevención a partir de sus particulares marcos de sentido y en circunstancias y momentos concretos, adaptando los mensajes para sus propios fines y estrategias sociales. Creemos que es preciso, entonces, tener presente que, en general, los sujetos pueden tener en momentos específicos prioridades distintas a la de la evitación de la infección o la determinación de su status frente al VIH, y que ello, además de legítimo, es comprensible desde los parámetros de sus vidas y debe ser tenido en cuenta en vías de hacer compatibles las medidas de sexo más seguro y la promoción de la prueba con las metas de los sujetos, ya sean éstas la experimentación en los límites de la sexualidad, dar materialidad a un compromiso con otra persona, la búsqueda de intimidad y reconocimiento, expresar la propia identidad o cualquier otra que no haya aparecido en el estudio. Esto debe traducirse en organizar la intervención orientándola en la dirección de facilitar que se hagan conscientes los condicionantes que pueden estar incidiendo en una decisión (mantener prácticas sexuales más seguras o hacerse la prueba), que puede tener repercusiones fundamentales en su calidad de vida y sus niveles de salud, de modo que los sujetos se apropien realmente de estos mensajes y los incorporen de manera duradera.

Abundando en esta cuestión, resulta esclarecedor hacer referencia al modo en que se hizo preciso modificar, en función de un conocimiento más profundo de la realidad, ciertas categorizaciones a priori de los sujetos manejadas en los inicios de esta investigación según se practicaran o no la prueba del VIH. Cuando se realizaban las entrevistas se hizo patente, en primer lugar, que los sujetos se mostraban resistentes a ser encasillados con claridad en alguna categoría, cuyos límites resultaron más fluidos de lo previsto. En segundo lugar, contemplando la cuestión como proceso, pudimos observar que las actitudes pueden cambiar y, de hecho, cambian, por incidencia de variaciones en el entorno personal, que hacen que ciertas cosas, como hacerse la prueba del VIH, pasen a ser más probables y 
más pensables ${ }^{11}$. De hecho, en dos de los casos estudiados, los sujetos tomaron la decisión de hacerse la prueba durante el periodo de esta investigación después de años retrasándola, quizá en parte a resultas de nuestras preguntas. Y, en tercer lugar, los que se realizan la prueba de una forma en principio regular lo hacen impulsados por motivos tan 'problemáticos' como los que llevan a otros a retrasar su realización; entendiendo aquí "problemáticos" en el sentido de necesitados de explicación. Claramente, nuestros criterios a priori, desde una racionalidad prevencionista, no coincidieron con las racionalidades sociales y culturales de nuestros sujetos.

A la hora de abordar la investigación ligada a la intervención en prevención del VIH en población de HSH es imprescindible el manejo de una teoría solvente y explícita del sujeto social. La comprensión de las construcciones de sentido y su matriz social no es un mero ejercicio académico, sino que apuntala el trabajo de los agentes implicados en la prevención.

\section{REFERENCIAS BIBLIOGRÁFICAS}

ANDERSON, T., D. ATKINS y C. BAKER-CIRAC et al., (2001), "Revised Guidelines for HIV Counseling, Testing and Referral”, Mortality and morbidity weekly report, vol. 50 (RR-19), pp. 1-53.

BEARDSELL, S. (1999), "Sexual Risk Taking and HIV Testing: A Qualitative Investigation", en P. AGGLETON, G. HART y P. DAVIES (ed), Families and Communities Responding to AIDS, Londres, UCL Press.

BOLETÍN EPIDEMIOLÓGICO DE LA COMUNIDAD DE MADRID, 5 (9) (2003), http://www. madrid.org/sanidad/salud/vigilancia/boletin/pdf/Mayo2003.PDF

7 (8) (2002), http://www.madrid.org/sanidad/salud/vigilancia/boletin/pdf/Julio2002.PDF

CALVEZ, M. (1996), "La rationalité des conduites de prévention et l'experience sociale", en M. CALVEZ, M.A. SCHILTZ e Y. SOUTEYRAND (eds.), Les homosexuels face au sida. Rationalités et gestions des risques, France, Agence Nationale de Recherches sur le Sida, Collection Sciences Sociales et Sida.

CESES (Centre Européen pour la Surveillance Epidemiologique du SIDA/European Centre for the Epidemiological Monitoring of AIDS. HIV/AIDS), (2003), Surveillance in Europe. Mid-year report 2003, Saint-Maurice, Institut de Veille Sanitaire, vol. 69.

FENNEMA, H., H. Van der HOEK y J. Van der HEIJDEN et al. (2000), "Regional differences in HIV testing among European patients with sexually transmitted diseases: trends in the history of HIV testing and knowledge of current serostatus", AIDS 14,1993-2001.

\footnotetext{
"Esto fue posible comprobarlo empíricamente gracias a que se realizó un seguimiento de 8 de los sujetos investigados a través de tres entrevistas a intervalos de tres a cuatro meses.
} 
RIS

REVISTA INTERNACIONAL DE SOCIOLOGÍA

FERNYAK, S.E.; K. PAGE-SHAFER; T.A. KELLOGG; W. MCFARLAND; y M.H. KATZ (2002), "Risk Behaviors and HIV Incidence among Repeat Testers at Publicly Funded HIV Testing Sites in San Francisco", Journal of Acquired Immune Deficiency Syndromes, vol. 31, pp. 63-70.

FUENTES, P. (2001), "Modos de vida y relaciones sociales", en VVAA, En clave gay. Todo lo que deberiamos saber, Barcelona y Madrid, Editorial Egales.

GRHEK, M.D. (1989), Histoire du sida, París, Payot.

HART, G.J.; L.M. WILLIAMSON; P. FLOWERS; J.S. FRANCKIS, y G.I. DER (2002), "Gay Men's HIV testing behaviour in Scotland", AIDS Care 14 (s), pp. 665-674.

KEENAN, P., A. y J. M. KEENAN (2001), "Rapid HIV Testing in urban outreach: A strategy for improving posttest counselling rates", AIDS Education and Prevention, vol.13(6), pp. 541-550.

KELLERMAN, S., J. LEHMAN, J y A. LANSKY, et al. (2002), "HIV Testing Within At-Risk Populations in the United States and the Reasons for Seeking or Avoiding HIV Testing", Journal of AIDS, 31, pp. 202-210.

LAHIRE, B. (1998), L'homme pluriel: les ressorts de l'action, París, Nathan.

LANCASTER, R. N. (1992), Life is Hard. Machismo, Danger and the Intimacy of Power in Nicaragua, Berkeley y Los Angeles, University of California Press.

LANCASTER, R. N. y M. Di LEONARDO (1997), "Introduction. Embodied Meanings, Carnal Practices", en Lancaster y Di Leonardo, The Gender/Sexuality Reader. Culture, History, Political Economy, Nueva York y Londres, Routledge.

MACKELLAR, D.; L. VALLEROY; G. SECURA; B. BARTHOLOW, y W. McFARLAND et al. (2002), "Repeat HIV Testing, Risk Behaaviors, and HIV Seroconversion Among Young Men Who Have Sex With Men", Journal of AIDS, vol. 29, pp. 76-85.

MARKS, G.; J. RICHARDSON, y N. CREPAZ, et al. (2002), "Are HIV care providers talking eith patients about safer sex and disclosure?: A multi-clinic assessment", AIDS, vol. 16, pp.1953-1957.

MIRABET A. et al., (2000), Homosexualitat a l'inici del secle XXI, Barcelona, Editorial Claret.

PROYECTO EPI-VIH (2003), Evolución de la prevalencia de VIH en pacientes de diez centros de enfermedades de transmisión sexual y/o de diagnóstico del VIH, 1992-2002. www.msc.es/sida, Accedido en septiembre de 2003.

RADER, M.; G. MARKS; G. MANSERGH; N. CREPAZ; L. MILLER; P. APPLEBY y S.MURPHY (2001), "Preferentes about the characteristics of fututre HIV prevention products among men who have sex with men", AIDS Education and Prevention, vol. 13(2), pp.149-159.

ROTHERAM-BORUS, M.J. y M. ETZEL (2003), "Rethinking the HIV counseling and testing model in the USA", The Lancet, vol. 361(15 feb), pp.611 . 
SHILTS, R. (198), And the Band Played on: Politics, Peaple and AIDS Epidemic, Nueva York, St. Martin's Press.

SILVESTRE.; A., M. B. GEHL; J. ENCANDELA y G. SCHELZEL (2000), “A Participant Observation Study Using Actors at 30 Publicly Funded HIV Counseling and Testing Sites in Pennsylvania", American Journal of Public Health, vol. 90(7), pp.1096-1099.

SKOLNIK, H.; K. PHILLIPS; D. BINSON y J. DILLEY (2001), "Deciding Where an How to Be Tested for HIV: What Matters Most?", Journal of AIDS, vol. 27, pp. 292-300.

SPIELBERG, F.; A. KURTH; P. GORBACH y G. GOLDBAUM (2001), "Moving from apprehension to action: HIV counseling and testing preferences in three at risk populations", AIDS Education and Prevention, vol. 13(6), pp.524-540.

SPIELBERG, F.; B. BRANSON y G. GOLDBAUM et al., (2003), "Overcoming Barriers to HIV Testing: Preferentes for New Strategies Among Clients of a Needle Exchange, a Sexually Transmitted Disease Clinic, and Sex Venues for Men who Have Sex with Men", Journal of AIDS, vol. 32, pp. 318-327.

SUMMERS, T.; F. SPIELBERG; C. COLLINS y T. COATES (2000), "Voluntary Counselling, Testing, and Referral for HIV: New Technologies, Research Findings Create Dynamic Opportunities", Journal of Acquired Immune Deficiency Syndromes, 25, S128-S135.

VILLAAMIL, F. (2005), La transformación de la identidad gay en España, Madrid, La Catarata.

WADDELL, Ch. (1993), "Testing for HIV infection among heterosexual, bisexual and gay men", Australian Journal of Public Health, vol. 17 (1), pp. 27-31. 